\title{
KAJIAN EKOLOGIS DALAM KAITANNYA DENGAN AKTIFITAS PARIWISATA DI TAMAN NASIONAL LAUT BUNAKEN, PROVINSI SULAWESI UTARA
}

\author{
Hendrawan Syafrie ${ }^{1)}$ \\ ${ }^{1)}$ Fakultas Perikanan dan Ilmu Kelautan, Universitas Satya Negara Indonesia \\ Jl. Arteri Pondok Indah Jakarta, 12240 \\ a.syafrie@gmail.com
}

\begin{abstract}
ABSTRAK
Penelitian ini bertujuan untuk mengkaji kondisi terumbu karang yang ada di Taman Nasional Bunaken dan mengaitkannya dengan aktivitas pariwisata. Hasil penelitian menunjukkan bahwa kondisi ekologi di lokasi penelitian masih dalam kategori sangat baik meskipun menjadi lokasi pariwisata. Nilai tutupan terumbu karang berada dalam kisaran $91 \%$, jenis ikan demersal terdapat sekitar 91 jenis terbesar dari famili Pomacentridae dan Labridae. Adapun struktur komunitas lainnya berupa mangrove dan tumbuhan lamun juga ditemukan di lokasi penelitian. Status kawasan konservasi yang diberlakukan pemerintah sejak tahun 1991 juga membuat masyarakat di wilayah ini menjadi lebih memperhatikan kelestarian lingkungan laut.
\end{abstract}

\section{Kata kunci : bunaken, pariwisata, ekologi}

\section{PENDAHULUAN}

Menurut Bryan et al (1998) dari segi luasan terumbu karang, Indonesia menempati urutan kedua setelah Australia, namun demikian tingkat tekanan yang dialami oleh terumbu karang Indonesia berada diurutan pertama. Cukup banyak kegiatan pada ekosistem terumbu karang seperti penelitian imiah, pariwisata, perdagangan industri, ekspor, dan lain-lain oleh berbagai pihak institusi ilmiah (LIPI), Universitas, LSM, swasta dan pribadi. Berbagai aktivitas tersebut tentu saja memberi dampak pada ekosisitem terumbu karang. Dahuri et al (1996) menyatakan bahwa Indonesia memilliki kurang lebih $50.000 \mathrm{~km}^{2}$ ekosistem terumbu karang yang tersebar diseluruh wilayah pesisir dan lautan diseluruh nusantara, terumbu karang yang mencakup jenis terumbu karang tepi (fringing reefs), terumbu karang penghalang (barier reefs), terumbu karang cincin (atoll), dan terumbu karang tambahan (patch reeefs) terdapat diperairan Indonesia. Aktifitas pariwisata sebagai salah satu yang memanfaatkan potensi terumbu karang ini harus mendapatkan perhatian oleh pemerintah agar tidak bersifat merusak.

Banyak negara di dunia yang menjadikan pariwisata sebagai instrumen pengembangan dan peningkatan ekonomi dan bagian dari industri global. Pulau-pulau kecil selalu dikaitkan dengan faktor-faktor seperti keindahan, eksotisme, estetika, keragaman habitat alami dll. Dibandingkan industri pariwisata lainnya, pariwisata bahari telah berkembang pesat dan menjadi salah satu industri terbesar didunia. Pariwisata telah memberikan manfaat yang besar dalam ekonomi dan 
telah menyebabkan peningkatan kesadaran masyarakat di Indonesia dalam melindungi lingkungan laut terutama kawasan konservasi laut.

Taman Nasional Laut (TNL) Bunaken merupakan salah satu kawasan yang telah lama dijadikan objek pariwisata. Wilayah ini memiliki 22 desa dengan jumlah penduduk diperkirakan mencapai 35.000 jiwa yang sebagian besar berprofesi sebagai pemandu wisata dan nelayan. Ekosistem laut merupakan salah satu potensi sumberdaya yang sangat penting bagi masyarakat Bunaken. Oleh karena itu, penelitian ini perlu dilakukan dengan tujuan untuk mengetahui kondisi terumbu karang yang berada di daerah sekitar TNL Bunaken dan mengaitkannya dengan aktifitas pariwisata yang terjadi disana.

\section{METODOLOGI}

Pengambilan data tutupan terumbu karang secara langsung dengan metode transek garis menyinggung (Line Intercept Transect). Menurut English et al, 1997 bahwa metode ini dapat digunakan untuk melihat persentase tutupan terumbu karang. Metode ini dikerjakan oleh 2 orang penyelam, dimana penyelam pertama membentangkan rollmeter sejajar dengan garis pantai sepanjang 25 meter. Selain data terumbu karang, pengumpulan data primer diperoleh dengan melakukan disksusi dengan para stakeholder sumber informasi di lokasi peneltian. Data yang diambil adalah data biofisik dan sosial ekonomi yang menggambarkan kondisi lingkungan yang sesungguhnya.

Indikator yang dapat digunakan untuk melihat kualitas dan kondisi karang antara lain adalah penutupan alga, karang lunak, karang batu, dan biota lainnya. Penghitungan tingkat kesuburan terumbu karang dapat dilakukan dengan mengolah data dengan cara menghitungan persentase penutupan (Percent cover), persentase karang mati, alga, fauna lain, unsur substrat, indeks mortalitas karang, dan kondisi parameter fisika dan kimia perairan yaitu :

a. Menghitung Persentase Tutupan, Karang mati, Alga, Fauna Lain, dan Unsur Substrat. Menurut

$\mathrm{Ni}=-\mathrm{x} 100 \%$

Keterangan :

$\mathrm{ni}=$ persentase penutupan ;

li = panjang karang berdasarkan bentuk pertumbuhan ;

$\mathrm{L}=$ panjang transek garis.

Penduga kondisi terumbu karang dapat dikategorikan sebagai berikut : a) Kategori Sangat Buruk : 0 - $10 \%$; b) Kategori Buruk : 11 - $30 \%$; c) Kategori Sedang : 31 - $50 \%$; d) Kategori Baik : 51 - $75 \%$; dan e) Kategori Sangat Baik : 76 - $100 \%$.

b. Identifikasi Terumbu Karang 
Indeks Shannon-Wiener digunakan untuk menghitung indeks keanekaragaman (diversity index) jenis, indeks keseragaman, dan indeks dominansi dihitung menurut Odum (1998) dengan rumus sebagai berikut :

1. Indeks keannekaragaman Shannon-Wiener :

$\mathrm{H}^{\prime}=-\Sigma(\mathrm{ni} / \mathrm{N}) \ln (\mathrm{ni} / \mathrm{N})$

2. Indeks keseragaman :

$\mathrm{E}=\mathrm{H}^{\prime} / \mathrm{Hmax}$

3. Indeks dominansi :

$\mathrm{D}=\Sigma[\mathrm{ni} / \mathrm{N}]^{2}$

\section{Keterangan :}

$\mathrm{H}^{\prime}=$ indeks keanekaragaman shannon-wiener

$\mathrm{E}=$ indeks keseragaman

$\mathrm{D}=$ indeks dominansi simpson

ni $=$ jumlah individu genus ke-i

$\mathrm{N}=$ jumlah total individu seluruh genera

$\mathrm{H}$ max $=$ indeks keanekaragaman maksimum

(= ln $\mathrm{S}$, dimana $\mathrm{S}=$ jumlah jenis)

Kriteria nilai indeks keanekaragaman Shannon-Wiener $\left(H^{\prime}\right)$ adalah sebagai berikut :
$\mathrm{H}^{\prime}<1$
: keanekaragaman rendah
$1<\mathrm{H}^{\prime} \leq 3$
: keanekaragaman sedang
$\mathrm{H}^{\prime}>3$
: keanekaragaman tinggi

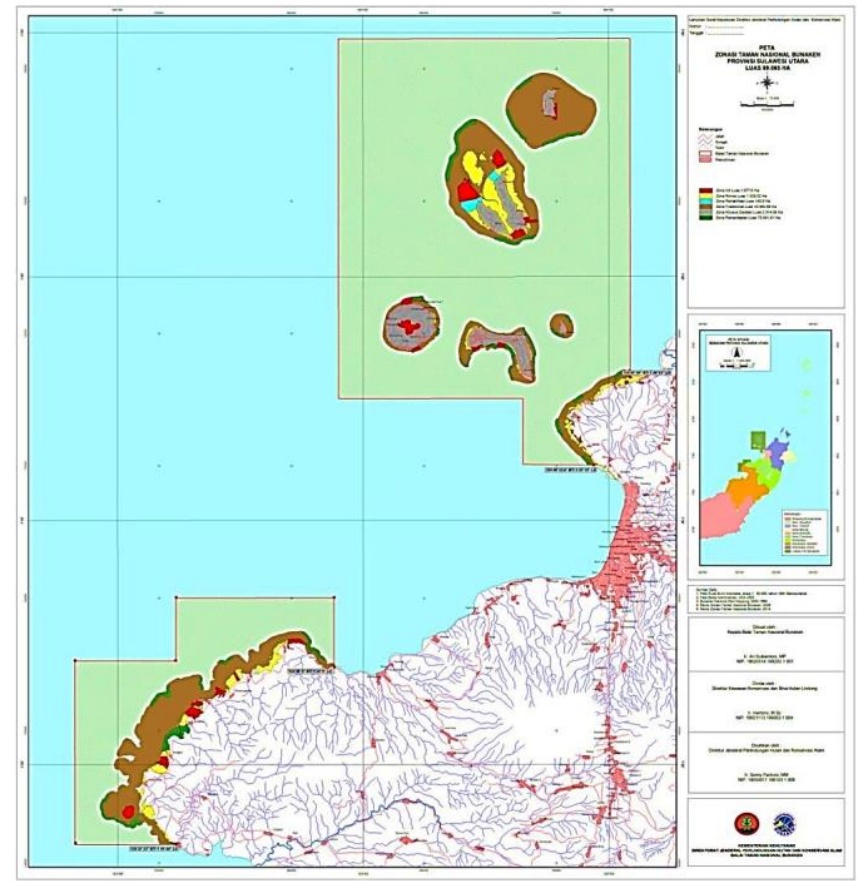


Gambar 1. Lokasi Survey Biofisik dan Sosial Ekonomi TN Bunaken

\section{METODOLOGI}

\section{ALAT DAN BAHAN}

Peralatan yang digunkan selama penelitian adalah : Buku identifikasi genera/spesies karang dan substrat, Alat dasar selam (masker, snorkel dan fins), Alat SCUBA, Papan sabak, Kertas tulis bawah air, Pensil, Roll meter (100 meter), GPS atau kompas, Kamera bawah air, dan Lembar kuisioner.

\section{HASIL PEMBAHASAN}

\section{A. Terumbu Karang}

Tercatat 13 genera karang hidup di perairan Taman Nasional Bunaken yang didominasi oleh terumbu karang tepi dan terumbu karang penghalang. Hasil identifikasi terumbu karang yang telah dihitung dengan menggunakan rumus yang ada dapat dilihat pada tabel 1 dibawah ini.

Tabel 1. Hasil Survei Terumbu Karang

\begin{tabular}{lr}
\hline \multicolumn{1}{c}{ Jenis Coral } & \multicolumn{1}{c}{ Luas Tutupan } \\
\hline Hard Coral & $\mathbf{5 9 , 6 7 \%}$ \\
\hline Acropora & $38,33 \%$ \\
\hline Non Acropora & $21,33 \%$ \\
Soft Coral & $\mathbf{0 , 6 7 \%}$ \\
\hline Death Coral & $\mathbf{8 , 6 7 \%}$ \\
\hline Algae & $\mathbf{2 9 , 6 7 \%}$ \\
Other Biota & $\mathbf{1 , 3 3 \%}$ \\
Sponge & $1,33 \%$ \\
Total penutupan (\%) & $\mathbf{1 0 0 , 0 0 \%}$ \\
H' Index & $\mathbf{3 , 5 8}$ \\
H' Max & $\mathbf{3 , 5 8}$ \\
Similarity Index (E) & $\mathbf{1 , 0 0}$ \\
\hline Dominancy Index $(\mathbf{C})$ & $\mathbf{0 , 2 7}$ \\
\hline
\end{tabular}

Berdasarkan data yang diambil terlihat bahwa persentase karang mati yang ada di lokasi penelitian adalah sebesar 8,67 \%. Hal ini berarti bahwa tingkat kematian terumbu karang yang terjadi di taman nasional laut bunaken masih dalam kondisi rendah. Berdasarkan pantauan dilapangan, penyebab utama kerusakan ini diperkirakan akibat aktivitas pariwisata dan penggunaan alat tangkap yang tidak ramah lingkungan. Disamping itu, tutupan terumbu karang yang hidup masih dikisaran 91\%. Terumbu karang ini terdiri atas Acropora, non accropora, soft coral, alga dan biota lainnya. Jenis Acropora dan alga terlihat sangat mendominasi tutupan 
karang yang ada. Nilai keanekaragaman $\left(\mathrm{H}^{\prime}>3\right)$ dan tingkat dominansi yang kecil $(0,27)$, yang dapat diartikan bahwa tingkat keanekaragaman di lokasi pengambilan data sangat tinggi. Hal ini juga memberikan gambaran bahwa kondisi terumbu karang diwilayah tersebut dalam kategori sangat baik.

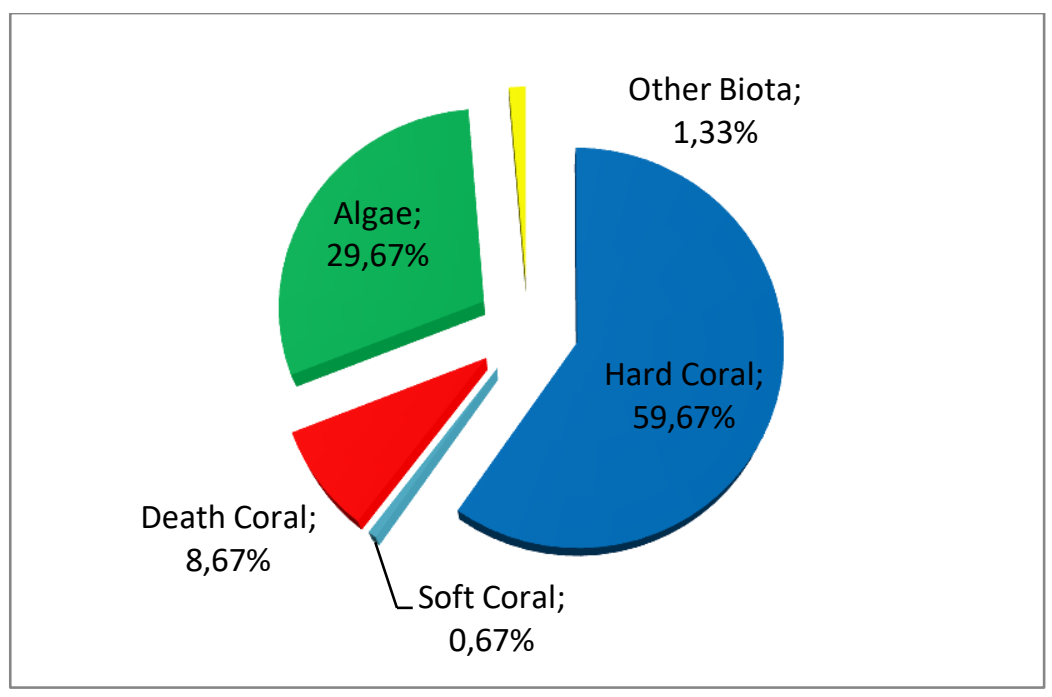

Gambar 2. Diagram Persentase Penutupan Terumbu Karang di TN Bunaken

Berdasarkan persentase tutupan karang yang digambarkan pada diagram diatas terlihat bahwa hard coral (karang keras) berupa Acropora Branching menjadi bagian yang paling besar. Dari 3 stasiun pengamatan, terlihat bahwa lokasi pertama memiliki tingkat kerusakan terumbu karang yang paling banyak. Data tersebut diambil di wilayah timur pulau bunaken yang dapat menggambarkan kondisi terumbu karang yang ada. Lokasi ini merupakan lokasi penyelaman yang menjadi rekomendasi bagi pendamping (guide) selam.
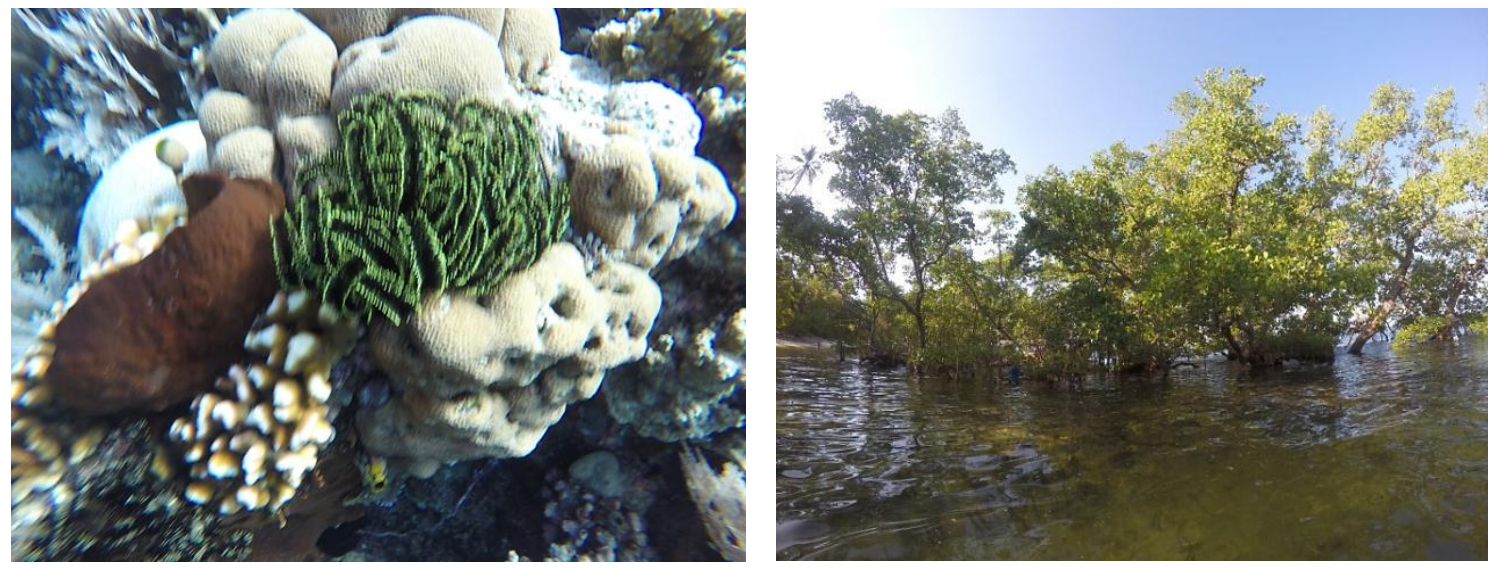

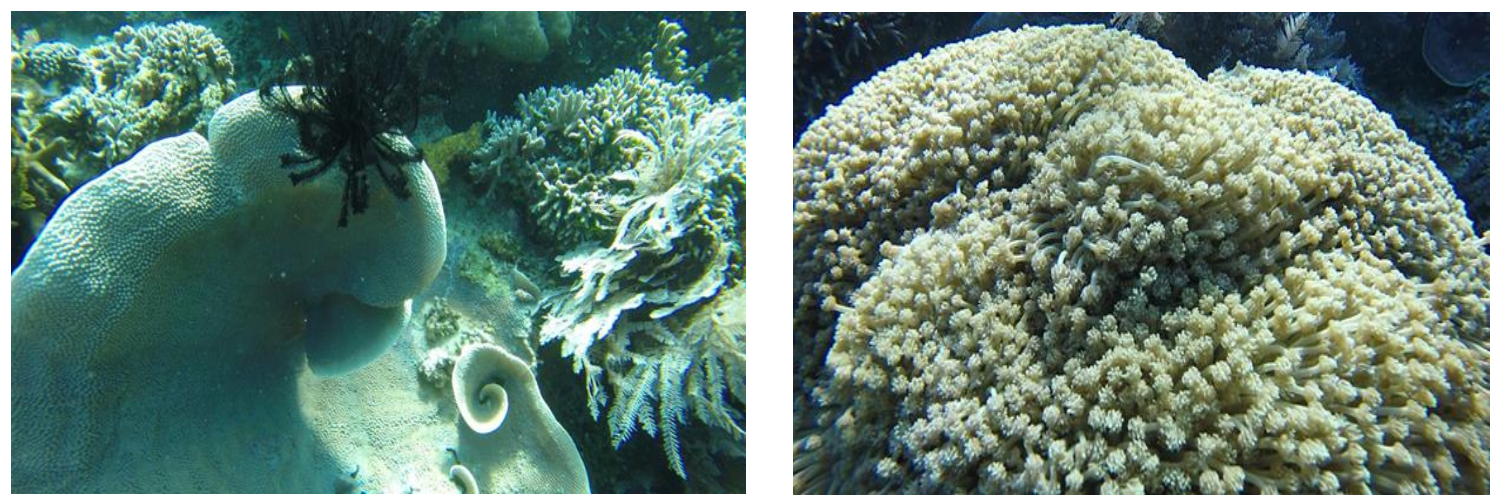

Gambar 3. Gambar kondisi Biofisik Perairan TN Bunaken, September 2016

Pulau-pulau kecil di Indonesia sangat rentan terhadap kerusakan terumbu karang akibat bencana alam dan aktivitas manusia. Kerusakan yang timbul dari manusia dapat berupa aktivitas penangkapan ikan yang merusak (destructive fishing), pemasangan jangkar kapal wisata, penambangan karang dan pasir. Pulau-pulau kecil biasanya memiliki keanekaragaman hayati pesisir dan laut tinggi. Dengan demikian, kegiatan yang merugikan serta mengancam ekologi, akan berdampak sosial bagi keberlanjutan ekonomi masyarakatnya.

Kegiatan manusia secara langsung dapat menyebabkan kematian pada terumbu karang seperti kegiatan penambangan karang batu, penangkapan ikan dengan bahan peledak dan bahan kimia beracun, penggunaan jangkar dan eksploitasi berlebihan terhadap sumberdaya tertentu (Sukarno, 1983). Penyebab lain kerusakan terumbu karang adalah karena adanya pencemaran (polusi) terhadap perairan pesisir. Pencemaran ini dapat berupa sampah domestik, industri, tumpahan minyak, dan buangan limbah dari bahan-bahan pertanian (Odum, 1971).

\section{B. Ikan Demersal}

1. Sekitar 91 jenis ikan terdapat di perairan Taman Nasional Bunaken, diantaranya ikan kuda gusumi (Hippocampus kuda), oci putih (Seriola rivoliana), lolosi ekor kuning (Lutjanus kasmira), goropa (Ephinephelus spilotoceps dan Pseudanthias hypselosoma), ila gasi (Scolopsis bilineatus), dan lain-lain. Berdasarkan hasil pengamatan yang terpantau pada bulan Agustus 2016 dalam satu lokasi pengamatan dengan luas daerah pengamatan yaitu $150 \mathrm{~m}^{2}$ per stasiun pengamatan. Mayoritas jenis ikan yang ditemukan pada semua titik pengamatan adalah dari famili Pomacentridae dan Labridae. Hal ini dikarenakan kedua famili ini memiliki jumlah jenis yang tinggi untuk kelompok ikan karang dan menempati hampir semua habitat di terumbu karang. Kedua jenis famili termasuk kedalam ikan pemakan plankton, Invetebrata, alga, moluska, bulu babi, dan udang kecil yang berada dalam habitat terumbu karang.

2. Kelompok ikan target yang ditemukan pada stasiun pengamatan ini mayoritas merupakan anggota dari famili Acanthuridae, Balistidae, Caesionidae, Haemulidae, dan Holocentridae. Kelimpahan masing - masing jenis ikan tersebut berbeda-beda dengan jumlah paling banyak adalah acanthuridae lineatus sebanyak 16 ekor.

\section{Mangrove}


Jenis tumbuhan di hutan bakau Taman Nasional Bunaken yaitu Rhizopora sp, Sonneratia sp, Lumnitzera sp, dan Bruguiera sp. Hutan mangrove ini kaya dengan berbagai kepiting, udang, moluska dan berbagai jenis burung camar, bangau, dara laut, dan cangak laut. Jenis ganggang yang terdapat di Taman Nasional ini meliputi jenis Caulerpa sp, Halimeda sp, dan Padina sp. Padang lamun yang mendominasi terutama di Pulau Montehege dan Pulau Nain yaitu Thalassia hemprichii, Enhallus acoroides, dan Thalassodendron ciliatum.

\section{Sosial Ekonomi}

Masyarakat di kelurahan bunaken sebagian besar berprofesi sebagai pemandu wisata dan penangkap ikan. Hal ini terlihat saat dilakukan pengumpulan data kuisioner yang melibatkan masyarakat. Pendapatan masyarakat disekitar wilayah taman nasional cukup untuk kebutuhan mereka sehari-hari. Sebagian besar masyarakat mengaku bahwa penetapan status konservasi di wilayah mereka sangat mempengaruhi aktifitas pariwisata di wilayah tersebut. Kegiatan ekonomi masyarakat yang sangat bergantung pada kondisi alam ini tentunya menyadarkan masyarakat akan pentingnya konservasi. Penetapan status kawasan konservasi berupa taman nasional telah ditetapkan berdasarkan SK. Menhut No 730/Kpts-III/1991.

Tabel 2. Hasil Identifikasi Ekonomi Sosial Budaya di TN Pulau Bunaken

\begin{tabular}{|c|c|c|c|}
\hline No & Pertanyaan & Jawaban & Keterangan \\
\hline \multicolumn{4}{|c|}{ 1. Pertanyaan Umum } \\
\hline 1 & Responden (30 orang) & Kepala RT & $73 \%$ \\
\hline 2 & Agama & Protestan & $80 \%$ \\
\hline 3 & Pendapatan & Rp. 2.988 .333 & \multirow{3}{*}{$\begin{array}{l}\text { Ada sisi dari hasil } \\
\text { pendapatan }\end{array}$} \\
\hline 4 & Pengeluaran & Rp. 1.683 .723 & \\
\hline 5 & Sisa & Rp. 1.304 .610 & \\
\hline 6 & Pemahaman tetang konservasi & Paham & $100 \%$ \\
\hline 7 & Manfaat & Ada manfaat, tambahan pendapatan & $100 \%$ \\
\hline 8 & $\begin{array}{l}\text { Tindakan menjaga daerah } \\
\text { konservasi }\end{array}$ & $\begin{array}{l}\text { Tidak melakukan perbuatan yang } \\
\text { merusak lingkungan }\end{array}$ & $100 \%$ \\
\hline 9 & Adanya konflik kepentingan & Tidak ada konflik $100 \%$ & $100 \%$ \\
\hline \multicolumn{4}{|c|}{ 2. Nelayan } \\
\hline 1 & Nelayan & 4 orang & \\
\hline 2 & Perahu & Ketinting & \\
\hline 3 & Alat & Pancing & \\
\hline 4 & Trip & One Day & \\
\hline 5 & Fishing ground & Bunaken sebelah timur, Laut sulawesi & \\
\hline 6 & Modal & Rp. 278.000 & \multirow{3}{*}{$\begin{array}{c}\text { Masih ada sisa hasil } \\
\text { usaha perikanan }\end{array}$} \\
\hline 7 & Hasil & Rp. 1.691.250 & \\
\hline 8 & Sisa hasil usaha & Rp. 1.413 .250 & \\
\hline
\end{tabular}




\section{KESIMPULAN}

Adapun kesimpulan dari penelitian ini adalah :

1. Kondisi terumbu karang di wilayah lokasi penelitian masih dalam kategori sangat baik.

2. Penetapan status kawasan konservasi menjadikan masyarakat lebih sadar akan perlindungan lingkungan laut.

\section{DAFTAR PUSTAKA}

Allen, G. R. and T. B. Werner. 2002. Coral Reef Fish Assessment in the 'Coral Triangle' of Southeastern Asia.Environmental Biology of Fishes 65(2): 209-214.

Odum, E.D. 1971. Fundamental of Ecology (3th Edition). WB. Sauders Company, Philadelphia.

Soekarno, N. Azis, Darsono, Moosa, Hoetomo, Mortosewojo, dan Romimoktanto. 1983. Terumbu Karang di Indonesia : Sumberdaya, Permasalahan, dan Pengelolaannya. LONLIPI, Jakarta. 